\title{
Indirect Estimation of Critical Frontal Process-Zone Size Using a Single-Edge V-Notched-Beam Technique
}

\author{
Hideo AWAJI, Seong-Min CHOI and Daniel Doni JAYASEELAN* \\ Nagoya Institute of Technology, Gokiso-cho, Showa-ku, Nagoya-shi 466-8555 \\ *National Institute of Advanced Industrial Science and Technology, Shimo-Shidami, Moriyama-ku, Nagoya-shi 463-8687
}

\author{
SEVNB 法を用いた臨界き裂先端損傷域寸法の間接評価 \\ 淡路英夫 ·崔 成珢·Daniel Doni Jayaseelan* \\ 名古屋工業大学，466-8555 名古屋市昭和区御器所町 \\ *産業技術総合研究所，463-8687 名古屋市守山区下志段味
}

\begin{abstract}
The size of the frontal process-zone at the crack tip of ceramics is an important factor to assess the toughening mechanisms operative in the material. An indirect technique is proposed here to estimate the critical size of the frontal process zone in ceramics using a single-edge V-notched beam (SEVNB) method. A three-point flexure test was carried out on alumina specimens containing a sharp $V$-shaped notch whose depth was varied. Then, a critical local stress was calculated at a critical distance from the notch tip. The frontal processzone size at the beginning of crack propagation, namely, the critical frontal process-zone size, was determined as the distance between the notch tip and the point where the critical local stress has the same value as the flexural strength of the specimen. This concept is based on a local fracture criterion. The calculated critical frontal process-zone size of alumina ceramics was $11.4 \mu \mathrm{m}$ based on the linear elasticity, and $22.8 \mu \mathrm{m}$ based on the Dugdale model.

[Received December 25, 2000; Accepted March 22, 2001]
\end{abstract}

Key-words : Alumina, Frontal process zone, Critical frontal process-zone size, SEVNB method, Toughening mechanisms, Local fracture criterion

\section{Introduction}

In general, ceramic materials intrinsically have ionic and/ or covalent bonding and hence the plastic deformation of structural ceramics due to dislocation movement is extremely limited. The frontal process-zone in front of a crack tip in ceramics is considered to be formed mainly by microcracking ${ }^{1,2)}$ rather than by dislocation movement as in metals. Thus ceramics tend to fracture in a brittle manner. It is therefore required to improve the fracture toughness of ceramics for reliable engineering applications.

Over the past decade, the microstructure of "nanocomposites" has been the most attractive mechanism of toughened materials of ceramics. Niihara ${ }^{3)}$ developed a new concept of nanocomposites and showed a marked improvement in the mechanical properties of ceramics. The microstructure of the nanocomposites is composed of second-phase nano sized particles dispersed within the matrix grains or along the grain boundaries. The strengthening and toughening mechanisms of the nanocomposites are considered to be that the thermal expansion mismatch between the matrix and second-phase particles produces residual stresses around the inclusions, and that further annealing of the specimen leads to the development of sub grain boundaries around the second-phase particles. Dispersion of the nano sized particles in polycrystalline ceramics improves the intergranular strength, and the transgranular microcracks along the sub grain boundaries in the matrix enhance the fracture toughness of the material.

Although many researchers were skeptical about the nano-toughened mechanism, ${ }^{4)-6)}$ Nawa et al.7) have recently developed another nanocomposite material of the $3 \mathrm{Y}-\mathrm{TZP} /$ Mo system and obtained significant results of a maximum strength of $2.1 \mathrm{GPa}$ (three-point bending) and a fracture toughness of $11.4 \mathrm{MPa} \cdot \mathrm{m}^{1 / 2}$ as measured by the SEVNB (single-edge $\mathrm{V}$-notched-beam) technique, ${ }^{8,9)}$ making it possible to estimate the intrinsic fracture toughness of the material.
Recently, we have classified the types of toughening mechanisms in polycrystalline ceramics with $R$-curve behavior into three groups: ${ }^{10)}$ (A) The frontal process zone toughening mechanism, which creates a damaged zone in front of a crack tip and is related to the intrinsic fracture energy of a material. This mechanism generates intrinsic fracture toughness ${ }^{11}$ of a material. (B) The crack-surface bridging and/or interlocking toughening mechanism operating in a process-zone wake, which produces an extrinsic increase in crack resistance after a certain extension from the initial crack. (C) The macroscopic crack deflection mechanism, which decreases the energy-release rate and consequently releases the stress-intensity factor at the crack tip. This mechanism apparently enhances the fracture toughness.

The key aspects in this classification are that the relationship between the intrinsic fracture toughness and the frontal process zone in a material is clarified such that the energy expended to create the critical frontal process-zone size is the intrinsic fracture energy, and that the fundamental concept behind the improvement of the intrinsic fracture toughness of ceramics is to expand the frontal process zone.

The toughening mechanism in nanocomposites is mainly related to $(\mathrm{A})$, in which sub-grain boundaries formed around the second-phase particles ${ }^{3)}$ are expected to create many microcracks around the origins of stress concentration, such as a crack tip, then expand the frontal processzone size, and consequently, enhance the intrinsic fracture toughness of the material.

Although the observation of the frontal process zone is essential to clarify the toughening mechanism of ceramics, there is no suitable technique for estimating the frontal process-zone size of ceramics directly because of its minuteness and indistinctness. There have been several conjectures about the critical size of the frontal process zone in the past, ${ }^{12), 14)}$ but it is still obscure.

The aim of this paper is to present an indirect technique for estimating the critical size of the frontal process zone us- 
ing the SEVNB technique to clarify the toughening mechanism of ceramics.

\section{Theory}

2.1 Intrinsic fracture toughness

According to Griffith-Irwin mechanics, the energy equilibrium between the energy release rate and the fracture energy rate is commonly expressed as ${ }^{13), 15)}$

$$
\frac{K_{\mathrm{IC}}^{2}}{E^{\prime}}=2 \gamma_{\mathrm{I}}
$$

where $K_{\text {IC }}$ represents the mode I fracture toughness, $\gamma_{\text {I }}$ the fracture energy per unit area of a crack surface when the crack extends in the direction of the maximum energy release rate, $E^{\prime}=E$ the plane stress and $E^{\prime}=E /\left(1-v^{2}\right)$ the plane strain, where $E$ is the Young's modulus and $v$ the Poisson ratio. The superior point of the Griffith concept ${ }^{10)}$ is that the equation for the energy equilibrium is composed of two discrete parts: One part is the critical energy release rate, as expressed on the left-hand side of Eq. (1). The energy release rate is not dependent on the nonlinear stress state in the process-zone area in front of a crack tip and is precisely determined by the stress intensity factor that depends on only the outer boundary conditions, as long as the condition of small scale yielding is applicable. The second part is the fracture energy rate, as expressed on the right-hand side of Eq. (1), which is directly related to the damaged frontal process zone, and represents the crack resistance of the material and should be a material constant.

Many polycrystalline ceramics exhibit rising $R$-curve behavior, and the crack resistance of the material with $R$-curve is expressed as

$$
K_{\mathrm{R}}(\Delta a)=K_{\mathrm{i}}+\Delta K_{\mathrm{R}}(\Delta a)
$$

where $K_{\mathrm{R}}(\Delta a)$ is the fracture toughness of the material exhibiting $R$-curve behavior, $K_{\mathrm{i}}$ the intrinsic fracture toughness, ${ }^{11)}$ and $\Delta K_{\mathrm{R}}(\Delta a)$ the extrinsic increase of fracture toughness after a certain extension from the initial crack tip, $\Delta a$. The intrinsic fracture toughness, $K_{\mathrm{i}}$, is related to the energy required to create the damaged frontal process zone at the crack tip, and then the Griffith-Irwin formula for the beginning of the crack extension is expressed as

$$
\frac{K_{\mathrm{i}}^{2}}{E^{\prime}}=2 \gamma_{\mathrm{i}}
$$

where the left-hand side of Eq. (3) indicates the critical energy release rate at the beginning of the crack extension that has no crack-surface bridging on the process-zone wake, and the right-hand side of Eq. (3) denotes the fracture energy rate associated with the critical frontal processzone size.

On the other hand, $\Delta K_{\mathrm{R}}$ in Eq. (2) is caused by shielding effects of bridging and/or interlocking in a process-zone wake, and hence, the Griffith-Irwin formula is modified for a material with rising $R$-curve as

$$
\frac{K_{\mathrm{R}}^{2}}{E^{\prime}}=2\left(\gamma_{\mathrm{i}}+\gamma_{\mathrm{R}}\right) \text {. }
$$

The left-hand side of Eq. (4) indicates the critical energy release rate after a certain crack extension in the material with $R$-curve, and $\gamma_{R}$ the additional fracture energy per unit area of a crack surface, which is the frictional or interlocking energy consumed in a process-zone wake. Therefore, $\Delta K_{\mathrm{R}}$ represents an extrinsic increase in crack resistance and is not a unique function of $\Delta a$, as it depends on the specimen configuration or the loading condition used. Thus, the essential resistance must be intrinsic fracture toughness, $K_{\mathrm{i}}$, and should be treated as mode I fracture toughness, $K_{\text {IC }}$, a unique material property. ${ }^{13)}$

A machined notch has no bridging on the crack surface at the beginning of the crack extension. Therefore, the SEVNB method, using a machined sharp V-shaped notch provides intrinsic fracture toughness of the material, as long as a suitable notch-root radius is used. ${ }^{14)}$ This method is based on the fact that the stress distributions near the notch tip have an inverse square-root singularity when the notch angle is below about 30 degrees. ${ }^{17)}$ The stress distributions near the notch tip are, then, explicitly characterized by the stress intensity factors in the same way as for a crack tip, which will be shown in the next section.

\subsection{Crack and notch}

The exact solution of the stress, $\sigma_{\mathrm{y}}$, on the $r$-axis in an infinite plate with a central crack under a uniform tensile stress, $\sigma$, as shown in Fig. 1 , is expressed as ${ }^{9)}$

$$
\sigma_{y}=\frac{\sigma(a+r)}{\left(2 a r+r^{2}\right)^{1 / 2}}=\frac{K_{\mathrm{I}}}{(2 \pi r)^{1 / 2}} \frac{1+r / a}{(1+r / 2 a)^{1 / 2}}
$$

where $K_{\mathrm{I}}=\sigma(\pi a)^{1 / 2}$ is the stress intensity factor and $a$ the half-crack length. In the case of $r \ll a$, the following Irwin's expression is derived:

$$
\sigma_{y}=\frac{K_{\mathrm{I}}}{(2 \pi r)^{1 / 2}} .
$$

The exact solution of the stress, $\sigma_{y}$, along the major axis of an elliptical hole in an infinite plate under a uniform tensile stress is derived as ${ }^{16)}$

$$
\begin{aligned}
\sigma_{y}= & \frac{\sigma}{2}\left\{1+\frac{2(1+m)}{\alpha^{2}-m}\right\}+\frac{\sigma}{2}\left[1+\frac{m^{2}-1}{\alpha^{2}-m}\right. \\
& \left.\times\left\{1+\frac{m-1}{\alpha^{2}-m} \frac{3 \alpha^{2}-m}{\alpha^{2}-m}\right\}\right]
\end{aligned}
$$

where, $a$ and $b$ are the semi major and semi minor axes of the elliptical hole, respectively, and $m=(a-b) /(a+b)$. The stress distribution near an elliptical notch tip along the major axis, $\sigma_{y, n}$, shown in Fig. 2, can be approximated as ${ }^{18)}$

$$
\begin{aligned}
\sigma_{y, n} & =\sigma\left(\frac{a}{2 r+\rho}\right)^{1 / 2}\left(1+\frac{\rho}{2 r+\rho}\right)+\sigma\left(\frac{\rho}{2 r+\rho}\right)^{3 / 2} \\
& =\frac{K_{\mathrm{I}, \mathrm{n}}}{(2 \pi r)^{1 / 2}} \frac{1+\rho / r}{(1+\rho / 2 r)^{3 / 2}}+\sigma\left(\frac{\rho}{2 r+\rho}\right)^{3 / 2} .
\end{aligned}
$$

Furthermore, in the vicinity of the notch tip, Eq. (8) can be written as ${ }^{14}$

$$
\sigma_{y, n}=\frac{K_{\mathrm{I}, n}}{(2 \pi r)^{1 / 2}} \frac{1+\rho / r}{(1+\rho / 2 r)^{3 / 2}}
$$

where, $K_{\mathrm{I}, n}=\sigma(\pi a)^{1 / 2}$ represents the stress intensity factor of the elliptical notch and $\rho$ the root radius of the notch tip.

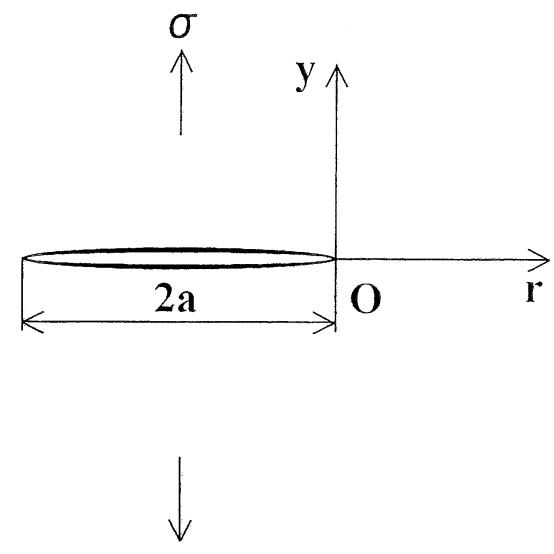

Fig. 1. Coordinates in the vicinity of a crack tip. 


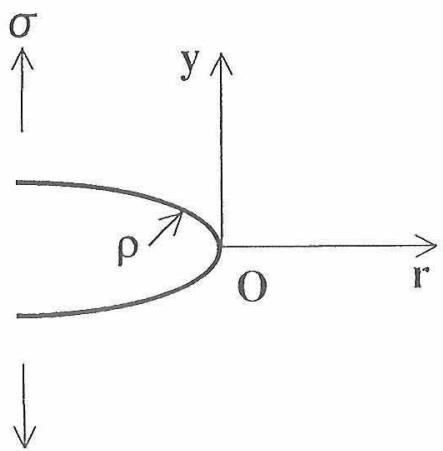

Fig. 2. Coordinates in the vicinity of a notch tip.

Equation (9) indicates that the stress distribution in the vicinity of the notch tip can be expressed using the stress intensity factor in the same way as for a crack tip.

A frontal process zone can be produced primarily by the occurrence of microcracking at the crack tip and at the notch tip in the same way, as shown in Fig. 3 , where $r_{0}$ indicates the critical frontal process-zone size. Assuming that the critical stresses, $\sigma_{\mathrm{c}}$, for both the crack and notch at the critical distance, $r_{0}$, from the tip have the same value, based on the local fracture criterion, ${ }^{19)}$ the following relationship is derived $^{16), 20)}$ from Eqs. (6) and (9):

$$
\frac{K_{\mathrm{C}, n}}{K_{\mathrm{IC}}}=\frac{\left(1+\rho / 2 r_{0}\right)^{3 / 2}}{1+\rho / r_{0}}
$$

where $K_{\text {IC }}$ is the fracture toughness of the material measured by a specimen with an ideally sharp and long crack, and $K_{c, n}$ the fracture toughness measured by a notched specimen. Equation (10) is valid under the condition of small scale yielding. The relationship between $K_{\mathrm{c}, n} / K_{\text {IC }}$ and $\rho / r_{0}$ is shown in Fig. 4, which indicates that the specimen with larger root radius gives larger $K_{c, n}$ values in the range of $4<\rho / r_{0}$, whereas in the range of $0<\rho / r_{0}<4, K_{\mathrm{c}, n} / K_{\text {IC }}$ can be roughly approximated to be equal to 1 .

\section{Experimental procedure and results}

\subsection{Strength vs notch depth}

The material used in this study was polycrystalline alumina of $99.5 \%$ purity with minor dopant of $\mathrm{MgO}$, manufactured by Japan Fine Ceramics Center and the mean grain size of $4 \mu \mathrm{m}$ with isotropic morphology and homogeneous microstructure. The fracture toughness measured using the SEPB (single-edge precracked beam) method was $3.65 \pm$ $0.11 \mathrm{MPa} \cdot \mathrm{m}^{1 / 2}$. Specimens $3 \times 4 \times 40 \mathrm{~mm}^{3}$ in size were machined out, chamfered and finished by polishing with lapping. A three-point flexure test, shown in Fig. 5, was carried out on the specimens with various depths of notch machined using a V-shaped diamond wheel, where the average root radius of the notch tip was about $20 \mu \mathrm{m}$.

The following stress intensity factor analyzed by Wakai et al. ${ }^{21)}$ was used for calculating the fracture toughness.

$$
\begin{aligned}
K_{\mathrm{I}} & =Y \sigma_{\mathrm{f}} a^{1 / 2} \\
Y & =\sum_{i=0}^{4} A_{i} \lambda^{\mathrm{i}}, \lambda=a / W, A_{i}=a_{i}+b_{i} \ln \left(S / W-c_{i}\right) \\
\sigma_{\mathrm{f}} & =\frac{3 P S}{2 B W^{2}},
\end{aligned}
$$

where $Y$ represents the shape factor of the edge cracked (or notched) specimen, $a$ the length of the edge crack (notch), $W$ the height, $B$ the width, $S$ the span length, $P$ the applied

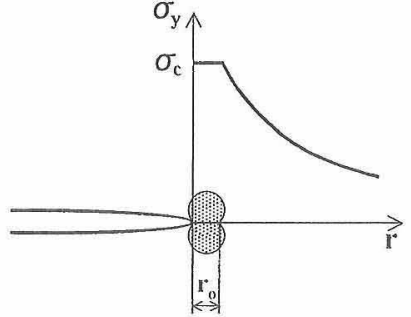

(a) crack tip

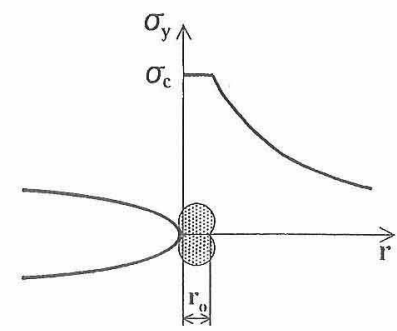

(b) notch tip
Fig. 3. Frontal process-zone sizes at (a) a crack tip and (b) a notch tip.

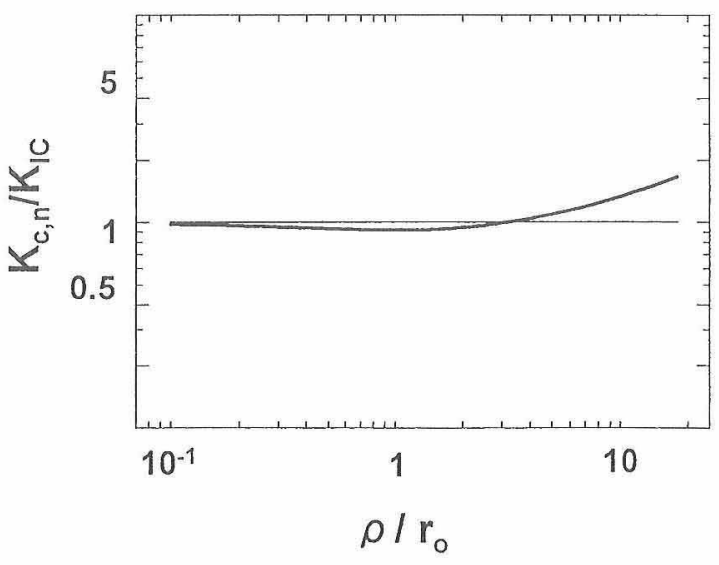

Fig. 4. Relationship between $K_{\mathrm{c}, n} / K_{\mathrm{IC}}$ and $\rho / r_{0}$.

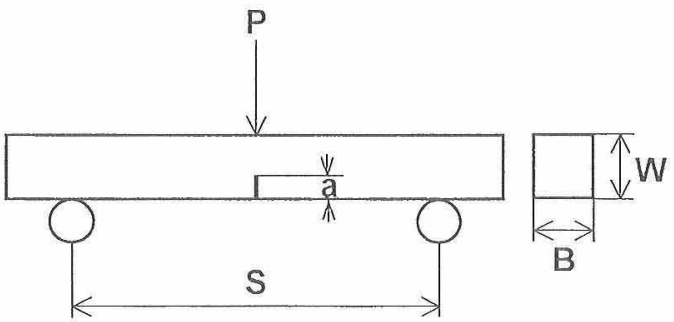

Fig. 5. Three-point flexure test for a specimen with an edge crack.

load, and $\sigma_{\mathrm{f}}$ the stress on the tensile surface of the flexure specimen. In this study, all specimens were set at $W=3 \mathrm{~mm}$ and $B=4 \mathrm{~mm}$ to compare the fracture strength of the specimens with and without the artificial notch for estimating the critical frontal process-zone size, where the fracture strength was measured using a JIS-type flexure specimen. ${ }^{22)}$ The values of $a_{i}, b_{i}$ and $c_{i}$ in Eq. (11) are given in Table 1.

Hereafter, we use an equivalent crack length in an infinite plate to remove the influence of the shape factors, $Y$, on the fracture strength of the notched specimen. The equivalent crack length is necessary for determining the relationship between the crack length and strength of the notched specimen. The equivalent crack length, $a_{\mathrm{e}}$, is defined in this case as 
Table 1. Coefficients for the Approximate Functions of $\mathrm{A}_{i}$

\begin{tabular}{cccc}
\hline$A_{i}$ & $a_{i}$ & \multicolumn{1}{c}{$b_{i}$} & $c_{i}$ \\
\hline$A_{0}$ & 1.943 & .01468 & 3.434 \\
$A_{1}$ & -3.091 & .1745 & -3.225 \\
$A_{2}$ & 14.46 & -.5167 & 3.247 \\
$A_{3}$ & -24.37 & .7781 & -3.278 \\
$A_{4}$ & 24.88 & -.5196 & 3.286 \\
\hline
\end{tabular}

$$
a_{\mathrm{e}}=\frac{Y^{2}}{\pi} a
$$

The strength, $\sigma_{\mathrm{c}}{ }^{*}$, of the infinite plate with the equivalent crack length for a long crack is defined as follows:

$$
\sigma_{\mathrm{c}}^{*}=\frac{K_{\mathrm{IC}}}{\left(\pi a_{\mathrm{e}}\right)^{1 / 2}} .
$$

Therefore, the plot of the relationship between $\log \sigma_{\mathrm{c}}{ }^{*}$ and $\log a_{\mathrm{e}}$ is a straight line with $-1 / 2$ gradient, as shown in Fig. 6.

The experimental results are shown in Fig. 6, where the marks (O) indicate the average strength of the specimens with various depths of V-shaped notch (five specimens per each notch depth). The deviations of the strength of the flexure specimens with the notch were in the range of $\eta=$ $0.0126-0.0528$, where $\eta$ is the coefficient of variation defined as $\eta=$ (standard deviation) / (average strength). The mark ( in Fig. 6 indicates the average flexural strength of the smooth-surface specimens (ten specimens), where the average strength was estimated to be $462 \pm 18.0 \mathrm{MPa}$.

It is observed from Fig. 6 that when the equivalent crack length is longer than $100 \mu \mathrm{m}$, the strength values of the flexure specimens with a notch lie on the straight line with $-1 / 2$ gradient, and therefore, linear fracture mechanics is applicable in this range. By curve fitting, the fracture toughness of alumina was estimated to be $3.72 \mathrm{~Pa} \cdot \mathrm{m}^{1 / 2}$, which is almost the same as the value obtained by the SEPB method previously mentioned.

3.2 Indirect estimation of frontal process-zone size

The remote flexural stress at the critical point from the notch tip, $r_{0}$, is simply assumed as follows, referring to Fig. 7:

$$
\sigma_{r_{0}}{ }^{*} \approx \sigma_{\mathrm{f}} \frac{W / 2-\left(a+r_{0}\right)}{W / 2},
$$

Then, the critical local stress at $r_{0}$ is calculated using Eq. (8) as

$$
\begin{aligned}
& \sigma_{\mathrm{c}}=\sigma_{r_{0}}{ }^{*} F\left(r_{0}\right) \\
& F\left(r_{0}\right)=\left(\frac{a}{2 r_{0}+\rho}\right)^{1 / 2}\left(1+\frac{\rho}{2 r_{0}+\rho}\right)+\left(\frac{\rho}{2 r_{0}+\rho}\right)^{3 / 2}
\end{aligned}
$$

where $\sigma_{\mathrm{f}}$ represents the flexure strength of the V-notched specimen, shown in Fig. (7), $\sigma_{r_{0}}{ }^{*}$ the approximated remote stress on $r_{0}$, and $F\left(r_{0}\right)=\sigma_{y, n}\left(r_{0}\right) / \sigma$ the nondimensional stress distribution at distance $r_{0}$ from the notch tip, calculated from Eq. (8). The approximation of $\sigma_{r_{0}}{ }^{*}$ is available only for a short notch compared with the height of the specimen. The critical local stresses calculated for several $r_{0}$ values are

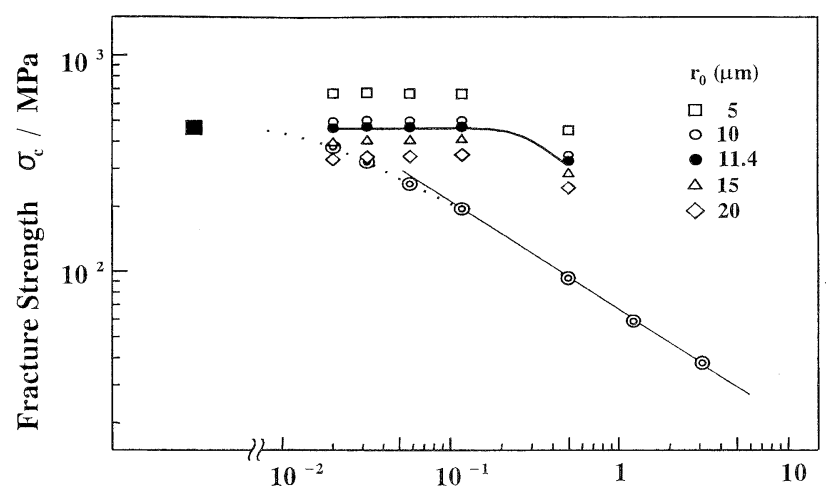

Equivalent Crack Length $a_{\mathrm{e}} / \mathrm{mm}$

Fig. 6. Relationship between fracture strengths and equivalent crack lengths, where the marks (O) indicate the average strength of the specimens with various $\mathrm{V}$-shaped notches, and the mark

- the average strength of the specimen with a smooth surface.

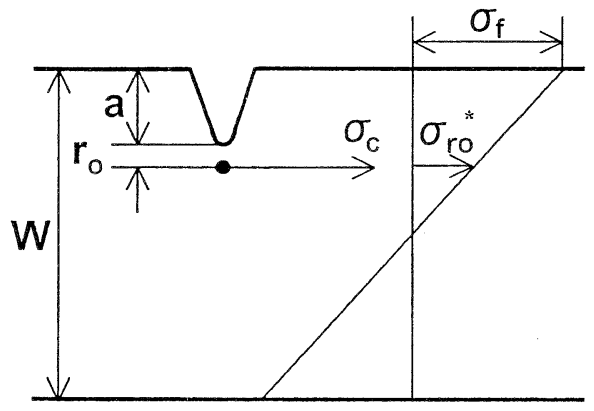

Fig. 7. Remote stress, $\sigma_{r_{0}}{ }^{*}$, at a critical point from a notch tip, $r_{0}$, in a flexure specimen with a notch.

indicated in Fig. 6 using different marks. The critical local stresses in the figure lie on the horizontal lines except that for the longest equivalent crack length, which suggests that the approximation of $\sigma_{r_{0}}{ }^{*}$ defined in Eq. (15) is invalid for the longest crack length. It is also recognized that the estimation of $\sigma_{\mathrm{c}}$ based on linear elasticity is successfully applicable to the case of ceramics with a small critical process zone.

It is evident that the critical local stress of $r_{0}=11.4 \mu \mathrm{m}$ indicated by the solid circles (O) in Fig. 6 is in good agreement with the flexural strength with no artificial notch shown by the solid square $(\boldsymbol{a})$. Therefore, the value of 11.4 $\mu \mathrm{m}$ is estimated to be the critical distance, $r_{0}$, where the critical distance equals the critical frontal process-zone size along the $r$ axis, as shown in Fig. 3. The flexural strength of the smooth surfaced specimen is selected as the critical local stress. This is because even in a specimen with no edge notch, there is a damaged process zone around the origin of fracture, and also the difference is small between the calculated strength values on the specimen surface and at a distance of $11.4 \mu \mathrm{m}$ from the surface. It is also noticeable that this critical process-zone size coincides with the conjectures presented previously. ${ }^{12), 14)}$

However, these calculations are based on the linear elasticity with no consideration of the nonlinear process zone at the crack tip. An actual critical process-zone size, $\left(r_{0}\right)_{\text {actual }}$, is expressed as 


$$
\left(r_{0}\right)_{\text {actual }}=2 r_{0}=\frac{K_{\mathrm{IC}}{ }^{2}}{\pi \sigma_{\mathrm{C}}{ }^{2}}
$$

based on the Dugdale model, ${ }^{23)}$ which modifies the extent of the plastic zone at the crack tip. Therefore, the actual critical process-zone size is estimated as $\left(r_{0}\right)_{\text {actual }}=22.8 \mu \mathrm{m}$ for the material considered.

\section{Conclusions}

An indirect technique has been proposed to estimate the critical size of a frontal process zone using the $\mathrm{V}$-shaped notch technique previously proposed by Awaji et al. A three-point flexure test was carried out on alumina specimens with various depths of the sharp V-shaped notch. The critical local stress was estimated at the critical distance from the notch tip using the stress distributions with high accuracy near the notch tip. The critical frontal processzone size was determined to be the distance at which the critical local stress has the same value as the flexural strength of the specimen, and was estimated to be $11.4 \mu \mathrm{m}$ based on the linear elasticity, and $22.8 \mu \mathrm{m}$ based on the Dugdale model.

\section{References}

1) Hoagland, R. G. and Embury, J. D., J. Am. Ceram. Soc., 63, 404-09 (1980).

2) Evans, A. G. and Faber, K. T., J. Am. Ceram. Soc., 67, 255-60 (1984).

3) Niihara, K., J. Ceram. Soc. Japan, 99, 974-82 (1991).

4) Pezzotti, G., Sergo, V., Ota, K., Sbaizero, O., Muraki, N., Nishida, T. and Sakai, M., J. Ceram. Soc. Japan, 104, 497-503 (1996).

5) Carroll, L., Sternitzke, L. C. M. and Derby, B., Acta Materialia, 44, 4543-52 (1996).
6) Perez-Rigueiro, J., Pastor, J. Y., Llorca, J., Elices, M., Miranzo, P. and Moya, J. S., Acta Materialia, 46, 5399-411 (1998).

7) Nawa, M., Yamazaki, K., Sekino, T. and Niihara, K., J. Mater. Sci., 31, 2849-58 (1996).

8) Awaji, H. and Sakaida, Y., J. Am. Ceram. Soc., 73, 3522-23 (1990).

9) Awaji, H., Watanabe, T., Sakaida, Y. and Nakagawa, H., Ceramics International, 18, 11-17 (1992).

10) Awaji, H., Choi, S.-M., Ebisudani, T. and Jayaseelan, D. D., J. Ceram. Soc. Japan, 108, 611-13 (2000) [in Japanese].

11) Ritchie, R. O., Mater. Sci. Eng., 103A, 15-28 (1988).

12) Usami, S., Kimoto, H., Takahashi, I. and Shida, S., Eng. Fract. Mech., 23, 745-61 (1986).

13) Awaji, H., "Strength of Ceramic Materials," Corona Publishing, Tokyo (2001) pp. 41-44 [in Japanese].

14) Awaji, H., Watanabe, T., Yamada, T., Sakaida, Y., Tamiya, H. and Nakagawa, H., Trans. Japan Soc. Mech. Eng., 56, 1148-53 (1990) [in Japanese].

15) Lawn, B., "Fracture of Brittle Solids," 2nd ed., in Chapter 2, Cambridge Univ. Press, New York, N. Y. (1993) pp. 16-50.

16) Williams, J. G., "Stress Analysis of Polymers," Longman, London (1973) p. 242.

17) Awaji, H., Yokobori, A. T. and Yokobori, T., Computers \& Structures, 22, 25-30 (1986).

18) Okamura, H., "Introduction to Linear Fracture Mechanics," Baifu-kan, Tokyo (1976) pp. 15-18 [in Japanese].

19) Beremin, F. M., Metal. Trans,. 14A, 2277-87 (1983).

20) Hasemi, S. and Williams, J. G., J. Mater. Sci., 20, 922-28 (1985).

21) Wakai, F., Sakaguchi, S. and Matsuno, Y., J. Ceram. Soc. Japan (Yogyo-Kyokai-Shi), 93, 479-80 (1985) [in Japanese].

22) JIS R 1607 (1990)

23) Broek, D., "Elementary Engineering Fracture Mechanics," 3rd revised ed., Martinus Nijhoff Publishers, Dordrecht, The Netherlands (1982) pp. 94-96. 